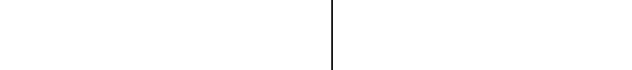

Rev. Latinoam. Psicopat. Fund., São Paulo, v. 10, n. 4, p. 624-636, dez.2007

\title{
À procura de um encontro perdido: o papel da "preocupação médico-primária" em UTI neonatal
}

\author{
Denise Streit Morsch \\ Maria Cristina (Nina) de Almeida Braga
}

Este trabalho tem por objetivo discutir o conceito de "preocupação médico-primária" (Agman et. al.) demonstrando sua função facilitadora das relações iniciais entre a mãe e o bebê internado. Parte do pressuposto de que este foco por parte da mãe sobre os parâmetros clínicos do recém-nascido é um rito de passagem que conduz à instalação da "preocupação maternoprimária" (Winnicott). Para as autoras trata-se de um recurso estratégico que permite aos membros da díade mãe-bebêauxiliados por parceiros como o pai, os avós, o próprio bebê e a equipe de cuidados intensivos - contornar as vicissitudes próprias a quem tem que se constituir como sujeito em meio a um ambiente potencialmente traumático como o de uma UTI neonatal.

Palavras-chave: Prematuridade, relação mãe-bebê, UTI neonatal, construção da subjetividade 
Tentamos achar nas coisas, que por isso nos são preciosas, o reflexo que nossa alma projetou sobre elas, e desiludimo-nos ao verificar que as coisas parecem desprovidas, na natureza, do encanto que deviam, em nosso pensamento, à vizinhança de certas idéias: e muitas vezes convertemos todas as forças dessa alma em habilidade, em esplendor, para influir em seres que sentimos fora de nós e que jamais alcançaremos. M. Proust, Em busca do tempo perdido: no caminho de Swann

\section{Introdução}

Toda e qualquer UTI neonatal é marcada por uma sucessão de desencontros entre o bebê pré-termo e seus pais. Não há antecipação de eventuais problemas ou preparação para o parto prematuro capaz de garantir que a dupla parental consiga conciliar seu bebê imaginário e imaginado com este bebê real que necessita de cuidados médicos para manter-se vivo. Sonhos e fantasias são - ao menos temporariamente - esmagados pela concretude de um ambiente intensivista, repleto de recémnascidos de aparência frágil e, por vezes, diminuta. As tramas das histórias que precedem os nascimentos tendem a esmorecer em meio ao emaranhado de fios de sensores, monitores e tubos de respiradores artificiais. Feridos em seu narcisismo, os pais têm 
dificuldade em reconhecer como seu um bebê distante de um ideal compartilhado e cultivado há vários anos. Em contrapartida, seu filho concentra toda sua energia para sua auto-regulação, estrategicamente relegando a um plano secundário eventuais interações. Estranha a ausência prematura da placenta e protege-se, à sua maneira, do excesso de estímulos que tanto destoam do ambiente intrauterino. Afinal, a passagem de feto a bebê se deu de maneira abrupta e potencialmente traumática.

Com tudo isso os integrantes da tríade pai-mãe-bebê sentem-se perdidos e - ao invés de um encontro - experimentam uma sensação de desnorteamento. A UTI neonatal é vivenciada como um labirinto cuja saída dificilmente será descoberta. Por entre suas aléias, que parecem nunca ter fim, há bebês que ainda não estavam prontos para nascer - tanto do ponto de vista orgânico quanto psíquico - e circulam pais atordoados com a perspectiva de ter de acolher prematuramente um bebê para o qual também não estavam preparados. A lástima, nem sempre manifesta, incide sobre um momento que "deveria ser" de regozijo. Há um acabrunhamento entre todos os membros da tríade. Encolhidos e recolhidos aos seus cantos, seus movimentos são curtos e hesitantes. Difícil firmar o passo e ousar distender os tímidos gestos. Estes são de cunho defensivo e, ocasionalmente, exploratório. Jamais muito ousados. Em nada lembram uma "dança harmoniosa" ou uma "sintonia afetiva". ${ }^{1}$ Os raios de alcance são limitados e restritos. Raramente os pais e seu bebê engendram qualquer contato entre si nas primeiras oportunidades. Não há encontros entre eles. E, sem encontros, não há vida e não há sujeitos. Assim como um ser vivo só se forma em função da confluência de diversas células e depende de trocas com o meio ambiente para sobreviver, a subjetividade só é constituída a partir da convergência de desejos e dela depende para tornar viável sua construção e existência. E no caminho do desejo para que o sujeito possa se originar privilegia-se a mulher-mãe na atenção e no cuidado. A ela são outorgadas funções de comunicação íntima com seu bebê para que a partir da intersubjetividade o bebê viva, seja em termos biológicos, seja em termos psíquicos. E esta "missão" torna-se extremamente difícil quando a

1. Esta imagem é bastante utilizada por pesquisadores de desenvolvimento do lactente para descrever o gestual da díade mãe-bebê. Nas palavras de Bydlowski, esta coreografia seria "biologicamente determinada", configurando "a base de uma sintonia afetiva (Stern, 1997) através do qual seriam transmitidos os sentimentos e crenças da jovem mãe”. Para essa psicanalista francesa “os momentos desta sintonia são intermitentes, mas são momentos fundantes, momentos de intensa emoção mútua onde é construída a pedra angular da personalidade da criança” (Bydlowski, 2000, p. 68). 
intimidade e a proximidade não têm como ocorrer, uma vez que tampouco se encontra o clima perceptivo-sensorial que é responsável pelas modalidades sensoriais e pelas capacidades integrativas indispensáveis a esta forma de comunicação inicial (Lamour e Barraco, 1998).

Logo, não há novidade em afirmar que o "bebê não existe sozinho”. Winnicott lembrou-nos disso desde os meados do século passado e indicou como as mães preparavam-se para tanto ao experimentarem nos últimos meses de gravidez e nos primeiros após o parto a "preocupação materno-primária”, ou seja, um estado de identificação com o bebê que lhes permite perceber e mesmo se antecipar - de maneira "suficientemente boa" - a qualquer necessidade por parte do seu filho (Winnicott, 1993, p. 492). E a crença acerca da importância da instalação desta "preocupação materno-primária” para o desenvolvimento de “indivíduos saudáveis” (Winnicott, 1999, p. 4) foi compartilhada e devidamente analisada por diversos expoentes dos estudos sobre as relações iniciais como Brazelton (1992), Klaus e Kennel (1992), Mathelin (1999), Spitz (1998) e Stern (1997), dentre outros. Contudo, o presente ensaio pretende introduzir - e, quiçá, inovar - uma discussão sobre um conceito correlato - o da "preocupação médicoprimária” (Agman et al., p. 27) - que nos é particularmente relevante porque foi construído com o intuito de dar conta das particularidades que caracterizam nosso universo de trabalho, ou seja, as UTIs neonatais.

\section{A questão da preocupação médico-primária}

O estado de “preocupação médico-primária” acontece quando a mãe “ocupa uma função mais médica que maternal” (Agman et. al., 1999, p. 27). Embora essas autoras não mostrem exemplos desta prática, pode-se ilustrá-la através do comportamento de inúmeras mães que permanecem ao lado da incubadora ou berço de seu bebê e sistematicamente perscrutam e examinam minuciosamente a ficha de enfermagem e/ou o prontuário no qual estão registrados os procedimentos adotados pelas equipes de cuidadores profissionais. Com freqüência, costuma-se encontrar duas ou mais mães junto ao balcão da enfermagem lendo e conversando sobre códigos, valores e marcações que fazem parte da papeleta de controle dos cuidados de cada um dos bebês. Ao observá-las é possível perceber que seus olhares investigativos conhecem o rumo a ser tomado. Dirigem-se exatamente àquelas variáveis que - no caso dos cuidados clínicos e respectivas respostas dos bebês - são considerados como da maior importância para seu filho nesse momento da internação. Muitas vezes esta atitude por parte da mãe parece ser exercida em detrimento de um olhar atento direcionado para seu filho, dando a 
impressão de que ocorreu uma “inversão de prioridades”. Isto porque supostamente estas mães estariam mais ocupadas em se imiscuir em condutas que são atributos de profissionais de saúde - de acordo com os parâmetros normativos da instituição hospitalar - ao invés de se ater ao que seria, a priori, de sua alçada: dedicar-se exclusivamente ao seu bebê, descobrindo suas competências e singularidades. Por conseguinte volta e meia escutam-se nas UTIs protestos por parte das equipes quanto ao que consideram como uma indevida intromissão e descuido para com as "obrigações” maternais: "aquela mãe tem de ser mais mãe e deixar de se preocupar com o que não lhe diz respeito".

Para Agman, Druon e Frichet, assim como para muitos profissionais de UTIs Neonatais, a mãe de um recém-nascido hospitalizado "pode rivalizar” com o serviço que trata de completar ou "finalizar o trabalho" não concluído por ela. Os profissionais em ação na UTI seriam vistos pelas mães como "juízes impiedosos do seu fracasso", perante os quais não se pode manifestar de forma explícita "sua agressividade sob pena de se sentir muito má em relação a quem permite ao seu bebê sobreviver” (Agman et. al., 1999, p. 27-9). Em outras palavras, as relações entre as mães e os cuidadores profissionais muitas vezes são permeadas por uma ambigüidade que também está presente no relacionamento com seu próprio filho. Mas não poderia ser diferente quando se tem de lidar com um bebê que "não sendo, em momento algum tranqüilizante, não fabrica a mãe” (Mathelin, 1999, p. 67) e esta, por si só, também não conseguirá "se fabricar". Na maioria dos casos há uma correspondência entre uma mãe prematura e um bebê pré-termo (Morsch, 1990).

Entretanto, precisa-se estar atento para não adotar uma perspectiva valorativa ao encarar esta "preocupação médico-primária" como uma recusa ao desempenho da função materna. Ao escarafunchar a papeleta encontrada sobre a incubadora, ao apropriar-se do glossário dos médicos para dialogar com os mesmos ou ao reunir ferramentas para melhor compreender a situação clínica de seu filho a mãe não está deixando de exercer a maternagem. Não está preenchendo uma "função mais médica que materna” (grifo nosso), como afirmaram as autoras do conceito em discussão. É imprescindível contextualizar e redimensionar esta prática. O que temos aqui é uma modalidade interativa que se tornou possível graças a uma disposição materna de envolver-se com seu filho. Sem poder usufruir os aspectos prazerosos como troca de olhares, proximidade física, diálogos tônicos e expressões faciais - os quais, indubitavelmente, estariam mais evidentes com o nascimento a termo - a mãe do bebê internado procura um caminho para se aproximar daquele que "não lhe envia nada da própria imagem dela" (Mathelin, 1999, p. 28). Através das informações que fazem parte de uma história que também é peculiar em função da hospitalização no início da vida, busca encontrar 
sinais de um bebê que aos poucos vai reconhecendo como seu, individualizandoo gradativamente.

Neste sentido, Winnicott - a quem devemos nosso holding teórico para muitas de nossas práticas na UTI neonatal - ao falar sobre o período de dependência absoluta da relação materno-infantil no início da vida - lembra a necessidade de que o ambiente se responsabilize por satisfazer as necessidades fisiológicas do bebê. E entende sempre o ambiente como impregnado pelos cuidados maternos:

Aqui a fisiologia e a psicologia ainda não se tornaram separadas, ou ainda estão no processo de fazê-lo e é consistente. Mas a provisão ambiental não é mecanicamente consistente. Ela é consistente de um modo que implica a empatia materna (grifo nosso). Holding protege da agressão fisiológica. Leva em conta a sensibilidade cutânea do lactente - tato, temperatura, sensibilidade auditiva, sensibilidade visual, sensibilidade à queda (ação da gravidade) e a falta de conhecimento do lactente da existência de qualquer coisa que não seja ele mesmo... O holding inclui especialmente o holding físico do lactente, que é uma forma de amar. É possivelmente a única forma em que uma mãe pode demonstrar ao lactente o seu amor (1990, p. 48).

Ao mesmo tempo a mãe, ao tentar compreender o que está acontecendo com seu filho, atende a uma expectativa da sociedade:

A realidade da responsabilidade atordoa as mulheres tal qual uma chicotada. Apesar do suporte oferecido pelos médicos e pela família, apesar da ajuda de seu marido para realizar parte dos cuidados, a sociedade a designa como $a$ responsável (grifo nosso). Se alguma coisa não vai bem, há muitas possibilidades da culpa disto recair sobre seus ombros. Trata-se de uma realidade de difícil aceitação para uma jovem mãe. (Stern e Bruschweiler-Stern, 1998, p. 98)

E, mais ainda, pode-se notar na mãe um processo de elaboração em curso na medida em que representa o que Cyrulnik (2005) designou como um ato de "absorção psíquica", ou seja, a compreensão de um acontecimento, pois a atribuição de um sentido por parte do sujeito faz com que "se sinta melhor, porque seu mundo torna-se claro, orientado e ele sabe como agir a esse respeito" (p. 102).

Por sua vez, ao apropriar-se dos códigos de comunicação das equipes de cuidadores profissionais a mãe do bebê habilita-se, à sua maneira, para eventualmente poder participar das instâncias de decisão sobre as condutas terapêuticas. E nem sempre este empoderamento (empowerment) daquela que deveria ser mais mãe é bem assimilado pelos conjuntos de profissionais das UTIs, mais habituados a decidirem entre si os tratamentos a serem dispensados a cada paciente. Com isso, um certo desconforto reina por vezes entre as equipes. Mas, 
em contrapartida, a mãe redefine seu lugar na UTI na medida em que troca a fragilidade e o alheamento inerente à parturiente prematura por uma posição mais assertiva. E seu poder - conquistado por estar a par e compreender o que se passa com seu filho - pode ser reconhecido tanto por ela quanto pelos outros. Assim, esta mãe passa a assumir o lugar que lhe pertence o que a capacita a encontrar sua competência e "maternar" seu filho, abrindo os caminhos para a interação.

Portanto, pensamos que a preocupação médico-primária só se instala provisoriamente no lugar da materno-primária porque a interação neste ambiente intensivista possui uma temporalidade própria. Ela é “urgente, premente, relacionada à sobrevivência do bebê e não à qualidade de seus cuidados" (Zornig et. al., 2004a, p. 139) ou mesmo "frenética” (Zornig et. al., 2004b, p. 172). E, por sua vez, possui especificidades para cada um dos integrantes desta relação em construção - sejam os pais, seja o bebê. De acordo com essas autoras:

Podemos pensar no parto prematuro como uma descontinuidade temporal dupla para o bebê, pois ao mesmo tempo provoca uma descontinuidade temporal que dificulta a instauração de cuidados parentais que facilitem o bebê a transição e a adaptação à vida extra-uterina, assim como antecipa uma prontidão ao exigir do bebê que ultrapasse sua fragilidade e imaturidade e se adapte às novas condições impostas pelo nascimento antecipado. (Zornig et. al., 2004a, p. 140)

Para contornar tais obstáculos, predominantes no ambiente intensivo, esta condição de funcionamento materno assume um papel de bússola, transformandose, como indicado, num instrumento interacional. Aos poucos, contatos são estabelecidos e os encontros delineados. Afinal:

... antes de conversarmos, é preciso nos aproximar; antes de trocarmos nossos mundos internos e contarmos nossas histórias, precisamos ver, saber a quem nos dirigimos, para escolher a parte de nosso mundo interno comunicável com o outro. Qualquer conversação, ainda que banal, exige a percepção e a codificação de um número incalculável de sinais para compreender seu significado. (Cyrulnik, 1995, p. 23)

Logo, se para a mãe a história do seu filho está sendo determinada por aspectos clínicos - os quais, por vezes, envolvem a possibilidade de morte do recém-nascido ou de eventuais seqüelas após a alta - ela sente necessidade de conhecer esta realidade e internalizar estas questões de cunho clínico de modo a atender às demandas de seu bebê. Em outras palavras, a resgatar a competência que lhe foi escamoteada pelo nascimento prematuro, uma vez que num primeiro momento só lhe restou entregar a terceiros a responsabilidade do cuidar de um bebê que não "soube” parir a contento. Ou seja, a preocupação médico-primária 
pode ser considerada um mecanismo de transição a ser utilizado pela mãe na busca por um encontro com um filho que nasceu de forma tão diferente e estranha. Ou como uma maneira de, neste contexto, dar início ao "fabricar" de uma mãe e seu bebê.

A própria Druon, em outro texto (1992), indica que “a tempestade emocional que se abate a maior parte do tempo sobre os pais e o bebê no momento do nascimento prematuro provoca uma ruptura no processo parental de pensar a propósito de seu filho e de seu futuro junto ao casal” (p. 248). Daí a urgência de achar uma via alternativa para que as tramas das histórias familiares não fiquem irremediavelmente comprometidas porque perdidas. Tanto que, por exemplo, a mãe de um bebê - cujo tempo de permanência na UTI neonatal foi de exatos cem dias - ao encontrar-se com algumas mães que ainda estavam com seus filhos internados as aconselhou: "Não tentem viver a história que não aconteceu. É preciso viver esta e descobrir muitas coisas boas que aconteceram. De outra forma não vamos poder viver o que é nosso".

\section{Considerações finais}

Sem dúvida é um caminho tortuoso e difícil como a dor daqueles que o percorrem. Além disso, há o risco da relação mãe-bebê cristalizar-se e perpetuarse de forma patológica caso a mãe não descubra aspectos de seu bebê para além das questões clínicas. Entretanto, não há tempo nem maneira definida a priori para que esta forma de maternagem seja suplantada pela preocupação materno-primária. Pode ser que a participação do pai, dos avós e mesmo das equipes de profissionais modifique o ritmo e o curso de uma história que é sempre singular. Tramas intergeracionais e transgeracionais podem, eventualmente, facilitar esta passagem. Especialmente porque a teia transgeracional resgata junto à incubadora do bebê o enredo que orienta as modalidades de maternagem deste grupo familiar. Ou seja, traz consigo lembranças necessárias para que o percurso rumo à maternidade e à paternidade seja novamente encontrado. Entretanto, este objetivo só pode ser alcançado mediante a evocação do "mundo representacional dos pais do bebê”, o qual inclui "suas fantasias, esperanças, medos, sonhos, lembranças da própria infância, modelos de pais, e profecias para o futuro do bebê” (Stern, 1997, p. 23).

Assim, em momento algum se pode pensar que estes registros sejam originados a partir da companhia das equipes de cuidadores profissionais. Estas recordações exigem a presença de quem se encontrava no tempo e no espaço de sua gestação. Como o pai do bebê. Por apresentar um comportamento que difere 
muito daquele que é próprio de sua mulher-mãe de seu filho, o companheiro-pai traz para a díade mãe-bebê a possibilidade de voltar a imaginar. Carrega dentro de seu pensamento imagens diferenciadas pela facilitação que a natureza ${ }^{2}$ lhe oferece para que acredite em seu bebê, já que na paternalidade a ambivalência é menor. Pode assim ajudar sua companheira a ver para além das paredes da UTI neonatal, isto é, para o mundo que os cerca e está à espera também do bebê. Ou, de acordo com os termos de Winnicott, oferecer-lhe um holding.

Outra parceria de suma importância neste momento são os pais dos pais dos recém nascidos. Graças ao fato de estarem ligados ao bebê e aos seus filhos numa trama que antecede e se prolonga para além do período de hospitalização, os avós ocupam um lugar especial. Muitas vezes são os que conseguem resgatar as histórias familiares, mostrando para os membros da tríade ainda em construção os laços que potencialmente os unem. Ou os que diante de uma incapacitação temporária de algum ou de todos os integrantes da tríade pai-mãe-bebê praticam a denominada "maternagem ampliada" (Braga et. al., 2001, p. 312) composta, basicamente, por uma modalidade de acolhimento voltada tanto para com os pais quanto para com o bebê.

Outrossim, apesar do fato de que o cuidado oferecido pelas equipes de agentes de saúde nunca estar no lugar de origem do mundo representacional dos pais com seu filho, é preciso reconhecer que uma postura de compreensão e acolhimento por parte dos profissionais das UTIs neonatais em muito facilita o nascimento psíquico dos bebês. Neste sentido assinala This (1987): "Nos serviços hospitalares onde o casal é acolhido, o homem pode transmitir segurança à sua esposa, e o nascimento pode se desenvolver naturalmente” (p. 240).

Entretanto, precisamos também lembrar a força do bebê face à sua capacidade de "maternalização" de sua mãe (Lamour e Barraco, 1998, p. 28). À medida que vai se despedindo dos aparelhos e que a tecnologia vai se afastando em função de suas novas competências o bebê finalmente consegue, através de gestos e expressões, dirigir-se aos seus pais e, especialmente, à mãe. Quando a mão do bebê prende-se ao dedo materno, que ampara o seio que se oferece à sua boca, o encontro de olhares torna-se possível, fechando o circuito que se torna

2. Estamos nos referindo ao engrossment - um potencial inato do pai em relação a seu bebê, que se desenvolve no momento de seu nascimento, liberado quanto mais cedo se dá o contato entre ambos. "Os pais são conscientes das características físicas do bebê, percebido como perfeito; o recém-nascido provoca no pai profunda atração, passando a focar nele seu interesse e atenção; a paternidade é vivida como uma experiência de exaltação e sensação de euforia; diante do nascimento do filho, o pai adquire maior sentimento de auto-estima” (Oiberman, 1994). 
viável pela intimidade e proximidade. E neste reconhecimento mútuo cenas primevas são resgatadas e a função materna passa a ser melhor delineada.

Logo, as possibilidades e as potencialidades das boas práticas, como as exemplificadas acima, são inúmeras e diversificadas. De comum entre todas há a chance de elas serem decisivas para que finalmente os encontros se sucedam. Tanto que se pode questionar se a denominação mais adequada para o estado da relação mãe-bebê abordado neste trabalho não seria a da preocupação médico $e$ materno-primária (grifo nosso). Afinal, ao longo desta reflexão constatou-se que a mãe - ao apresentar uma postura em parte semelhante à dos médicos - não está "deixando de ser" mãe, mas sim buscando meios de exercer uma maternagem que se encontra obstruída pelas particularidades de um parto prematuro.

Por conseguinte, a preocupação médica $e$ materno-primária pode funcionar também como um atalho atabalhoado capaz de viabilizar a instalação da maternoprimária na medida em que diminui os obstáculos às trocas afetivas entre a mãe e seu bebê. É um rito de passagem próprio de qualquer UTI neonatal. E, como tal, precisa ser resgatado e compreendido como uma tentativa de comparecer a um encontro praticamente perdido porque antecipado sem qualquer acordo entre as partes, lembrando que:

O tempo passado e o tempo presente Estão ambos talvez presentes no tempo futuro E o tempo futuro contido no tempo passado. Se todo tempo é eternamente presente Todo tempo é irredimível.

T.S. Eliot, Quatro quartetos

\section{Referências}

Agman, M. et. al. Intervenções psicológicas em neonatologia. In: Wanderley, Daniele de Brito (org.). Agora eu era o rei: os entraves da prematuridade. Salvador: Ágalma, 1999. p. 17-34.

BRAGA, Nina de Almeida et. al. Maternagem ampliada - a transgeracionalidade em UTI neonatal. Pediatria Moderna, São Paulo, v. XXXVII, n. 7, p. 312-7, jun. 2001.

Brazelton, Tery Berry. O desenvolvimento do apego - uma família em formação. Tradução Dayse Batista. Porto Alegre: Artes Médicas, 1992.

BydLowski, Monique. Je revê un enfant: l'experience intérieure de la maternité. Paris: Odile Jacob, 2000. 
Cyrulnik, Boris. Os alimentos do afeto. Tradução Celso Mauro Paciornik. São Paulo: Ática, 1995.

O murmúrio dos fantasmas. Tradução Sônia Sampaio. São Paulo: Martins Fontes, 2005.

Druon, Catherine. Prise em charge psychologique: "La Couvese psychique" en néonatologie "7 ans de réflexion": Quelles observations? Quelles actions? Progrés en Néonatologie, Paris, n. 12, p. 247-51, 1992.

ELIot, Thomas Stearns. Quatro quartetos. Tradução Ivan Junqueira. Rio de Janeiro: Civilização Brasileira, 1967.

Klaus, Marshall e Kennell, John. Pais-Bebê: a formação do apego. Tradução Dayse Batista. Porto Alegre: Artes Médicas, 1992.

Lamour, Martine e Barraco, Marthe. Souffrances au tour du berceau. Paris: Gaëtan Morin Éditeur, 1998.

Mathelin, Catherine. O sorriso da Gioconda: clínica psicanalítica com os bebês prematuros. Rio de Janeiro: Companhia de Freud, 1999.

Morsch, Denise Streit. O desenvolvimento afetivo em situação de alto risco neonatal: um estudo sobre o processo de interação. 1990. 189 p. Dissertação (mestrado em Psicologia Clínica), Pontifícia Universidade Católica do Rio de Janeiro.

Oiberman, Alícia. La relación Padre-Bebe: una revision bibliográfica. Revista Hosp. Ramon Sarda, XVIII, n. 2, p. 66-72, 1994.

Proust, Marcel. Em busca do tempo perdido - No caminho de Swann. 5. ed. Tradução Mário Quintana. Porto Alegre: Editora Globo, 1981.

Spitz, René. O primeiro ano de vida: um estudo psicanalítico do desenvolvimento normal e anômalo das relações objetais. Tradução Erothildes Millan Barros da Rocha. São Paulo: Martins Fontes, 1998.

StERn, Daniel. A constelação da maternidade: o panorama da psicoterapia pais-bebê. Tradução Maria Adriana Veríssimo Varonese. Porto Alegre: Artes Médicas, 1997.

Stern, Daniel e Bruscchweiler-Stern, Nadia. La naissance d'une mère. Paris: Odile Jacob, 1998.

This, Bernard. O pai: ato de nascimento. Tradução Mário Fleig e Luiz Carlos Petry. Porto Alegre: Artes Médicas, 1987.

WinnicotT, Donald Woods. O ambiente e os processos de maturação. 3. ed. Tradução Irineo Constantino Schuch Ortiz. Porto Alegre: Artes Médicas, 1990.

Preocupação materna primária. In: Textos selecionados da pediatria à psicanálise. 4. ed. Tradução Jane Russo. Rio de Janeiro: Francisco Alves, 1993. p. 491-8. 
Tudo começa em casa. Tradução Paulo Sandler. São Paulo: Martins Fontes, 1999.

ZoRNIG, Silvia Abu-Jamra et. al. Os tempos da prematuridade. Revista Latinoamericana de Psicopatologia fundamental, São Paulo, v. VII, n. 4, p. 135-43, dez.2004a.

Zornig, Silvia Abu-Jamra et. al. Parto prematuro: antecipação e descontinuidade temporal? In: Aragão, Regina Orth (org.). O bebê, o corpo e a linguagem. São Paulo: Casa do Psicólogo, 2004b. p. 165-74.

\section{Resumos}

Este trabajo tiene como objetivo discutir el concepto de "preocupación médicoprimaria" (Agman et. al.), demostrando su función facilitadora en las relaciones iniciales entre la madre y el bebé internado. Parte de la presuposición que este foco por parte de la madre acerca de los parámetros clínicos del recién nacido es un paso ritual que conduce a la instalación de la "preocupación medica-primaria"(Winnicott). Para las autoras, se trata de un recurso estratégico que permite a los miembros de la díada madre-bebé - auxiliada por aliados como el padre, los abuelos, el propio bebé y el equipo de cuidados intensivos - aliviar las vicisitudes propias de quien tiene que constituirse como sujeto en medio a un ambiente potencialmente traumático como el de una UTI neonatal.

Palabras claves: Prematuridad, relación madre-bebé, UTI neonatal, construcción de la subjetividad

Ce travail vise à discuter le concept de "souci médico-primaire" (Agman et.al) et à démontrer son rôle facilitateur lors des premières relations entre la mère et le nourrisson hospitalisé. Il part du présupposé que ce regard de la mère focalisé sur les paramètres cliniques du bébé est un rite de passage, menant à l'installation du "souci materno-primaire" (Winnicott). Pour les auteurs, il s'agit d'un recours stratégique qui permet aux membres de la dyade mère-bébé - aidés par des partenaires comme le père, les grands-parents, le propre bébé et l'équipe de soins intensifs - de franchir les vicissitudes de celui qui doit se constituer comme sujet dans une ambiance potentiellement traumatisante - ainsi que celle d'une UTI néonatale.

Mots clés: Prématurité, relation mère-bébé, UTI néonatal, construction de la subjectivité

This article discusses the concept of "primary medical concern" (Agman et al.), including its function in facilitating an initial relationship between the mother and her still hospitalized newborn infant. It is argued that the mother's focus on the baby's 
clinical parameters operates as a rite of passage that leads to establishing "primary maternal preoccupation" (Winnicott). The authors argue that this is a strategic resource that allows the mother-infant dyad - helped by partners such as the father, grandparents, the infant itself and the intensive care team - to overcome tasks imposed on someone who has to establish his or her own self amidst the potentially traumatic environment of a neonatal ICU.

Key words: Prematurity, mother-infant relationship, neonatal ICU, construction of subjectivity

\section{Denise STReit Morsch}

Psicóloga; doutora em Saúde da Criança e da Mulher - IFF/Fiocruz (Rio de Janeiro, RJ, Brasil); pesquisadora visitante - Fiocruz/Faperj (Rio de Janeiro, RJ, Brasil); Ambulatório de Seguimento - Instituto Fernandes Figueira (Rio de Janeiro, RJ, Brasil).

Rua Dona Mariana, 136/304 - Botafogo

22280-020 Rio de Janeiro, RJ, Brasil

e-mail: denisemorsch@yahoo.com.br

\section{Maria Christina (Nina) de Almeida Braga}

Socióloga; psicóloga; mestre em Saúde da Criança e da Mulher, Instituto Fernandes Figueira/Fiocruz (Rio de Janeiro, RJ, Brasil), Departamento de Ensino e Pesquisa.

Rua Sambaíba, 400/301 - Leblon

22450-140 Rio de Janeiro, RJ

e-mail: ninabraga@terra.com.br 